\title{
AN EXPERIMENTAL INVESTIGATION OF THE EFFECT OF MASS FLOW RATES ON THE PERFORMANCE OF FLAT-PLATE SOLAR WATER HEATING SYSTEM USING CUO/WATER NANOFLUID
}

\author{
P.Michael Joseph Stalin ${ }^{{ }^{*}}$,T.V.Arjunan ${ }^{2}$, N. Sadanandam ${ }^{2}$ \\ ${ }^{1}$ Ranganathan Engineering College, Coimbatore-641 109 \\ pmjstalin@gmail.com \\ ${ }^{2}$ Coimbatore Institute of Engineering and Technology, Coimbatore-641 109 \\ arjun_nivi@yahoo.com \\ ${ }^{2}$ Coimbatore Institute of Engineering and Technology, Coimbatore-641 109 \\ nsadanandamcbe@gmail.com
}

\begin{abstract}
One of the effective ways of increasing the efficiency of flat plate solar collector is to utilize nanofluids which are having high thermal conductivity. In the present study, an attempt is made to investigate the effect of mass flow rates on the performance of flat plate solar collector using $\mathrm{CuO} /$ water nanofluid. The experimental set up consists of flat plate solar collector; storage tank and ladder type heat exchanger. The instantaneous efficiency of solar collector is calculated by taking lower volume fraction of $0.01 \%$ with average particle size of $30 \mathrm{~nm}$ and varying the flow rate from $1 \mathrm{lpm}$ to $3 \mathrm{lpm}$, as per ASHRAE standard, with and without Triton X-100 surfactant. The experimental results reveal that utilizing the nanofluid with mass flow rate at $1.5 \mathrm{lpm}$ increases the collector efficiency by $19.7 \%$.
\end{abstract}

\section{Indexing terms/Keywords}

\section{Forced circulation, Heat exchanger, Nanofluid, Solar collector, Surfactant}

\section{INTRODUCTION}

Solar water heaters play an important role in low temperature applications especially in domestic field. Solar radiation absorbs the incoming radiation, converting it into thermal energy at the absorbing surface, and transferring the energy to a fluid through the collector. Hot water is required for taking baths, washing clothes, and other domestic purposes in rural as well as in urban areas. Water is generally heated by burning non-commercial fuels, like, firewood as in the rural or village areas and commercial fuels such as liquid petroleum gas (LPG), kerosene oil, coal and electricity (by means of geysers or immersion rod heaters) in urban areas. In this regard, utilization of freely available solar energy in solar water heating systems plays a great role in the consumption of conventional energy requirement. Thus solar water heaters have great potential in reducing environmental pollution caused due to use of fossil fuels. Advanced material synthesis technology provides an opportunity to produce the nanosize materials, when suspended in conventional fluids, considered as nanofluids [1]. A substantial increase in liquid thermal conductivity, liquid viscosity, and heat transfer coefficient, are the important characteristics of nanofluids. It is observed that metals in solid phase have higher thermal conductivities than those of fluids [2]. The use of nanofluid has a dramatic improvement on the liquid thermo physical properties such as thermal conductivity $[3,4]$.

The effects of various nanofluids in several industrial and residential applications have been analyzed, experimentally and theoretically, by several researchers all over the world [5-14]. The thermal performance using nanofluids is mainly dependent on several thermo physical properties of nanoparticle such as shape, particle diameter, $\mathrm{pH}$ value, viscosity, thermal conductivity, volume fraction and specific heat capacity of the nanofluid. Different theories have been established to understand the behaviour of nanoparticles under temperature, $\mathrm{pH}$ and sonication etc. Theoretical analysis on the heat transfer coefficient based on the effect of particle size, extinction coefficient [15], brownian motion and Thermophoresis were developed [16].

However, the quantum of research done in the utilization of nanofluids in flat plate solar water heaters is still in the developmental stage. The literature shows that there is little work on the flat-plate solar collector performance using $\mathrm{CuO} /$ water as the working fluid. For carrying out the experimental investigation further, a commercial flat plate solar water heater was selected for this study. The main objective of study is to investigate the effect of the mass flow rates on the performance of solar water heater using $\mathrm{CuO} /$ water as the working fluid.

\section{EXPERIMENTAL SETUP}

The experimental setup, shown in Fig.1, was fabricated at Coimbatore Institute of Engineering and Technology and experimental investigations were carried under the meteorological conditions of Coimbatore, India during the period March 2016 to May 2016. The experiments were conducted as per ASHRAE standard and the test data collected for each test at steady state conditions. Based on the solar radiation similarity pattern the data were selected and presented in this study to get concurrent results. The experimental set up consist of flat plate solar collector, storage tank and ladder type heat exchanger. The dimensions of the solar collector are $2 \mathrm{~m}$ long, $1 \mathrm{~m}$ wide and $0.15 \mathrm{~m}$ high and the area of the collector is $2 \mathrm{~m}^{2}$. A copper sheet of $0.45 \mathrm{~mm}$ thick is used as the absorber plate and a transparent glass of $4 \mathrm{~mm}$ thick is used to cover the collector in order to reduce the loss of radiation. The absorber plate is black painted to absorb maximum solar radiation. The gap between the glass cover and absorber plate is $0.03 \mathrm{~m}$. The collector bottom and side are insulated using glass wool with a thickness of $50 \mathrm{~mm}$ and $25 \mathrm{~mm}$ respectively to reduce the heat loss due to convection. 


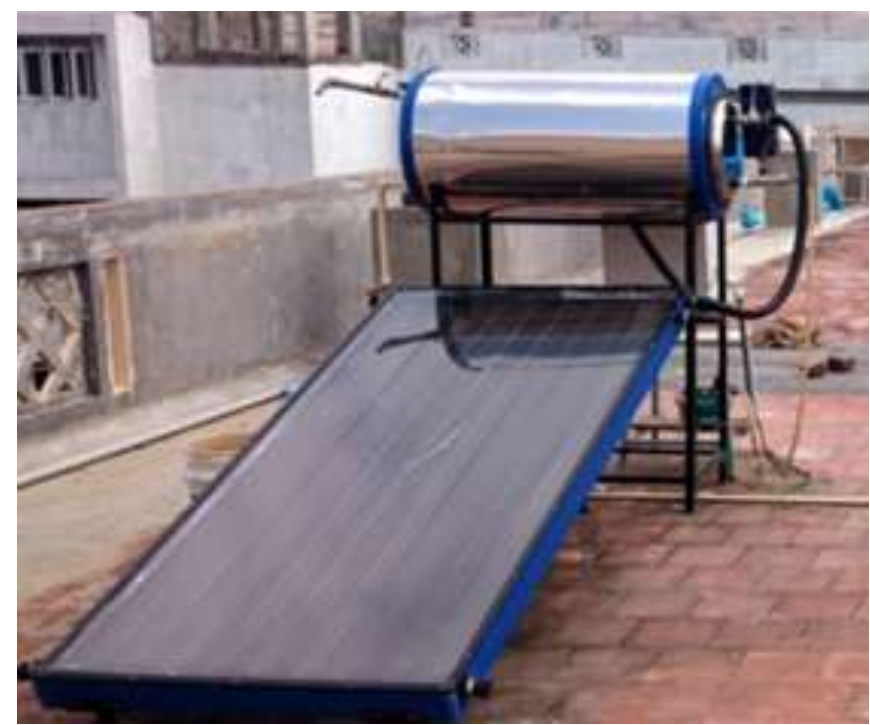

Fig.1. Experimental Setup

The storage tank consists of inner tank and outer tank, in which the inner tank is placed inside the outer tank. The $0.1 \mathrm{~m}$ gap is maintained between two tanks, which are filled by glass wool in order to reduce the heat losses from the hot water. The solar collector which consists of 9 parallel tubes (risers) of $10 \mathrm{~mm}$ diameter on the backside of the absorber plate is connected at the top and bottom by headers to provide homogenize flow distribution and static pressure at inlet and outlet section. The schematic diagram of the solar water heating system is shown in Fig. 3. A ladder type heat exchanger (Fig. 2) made up of copper tubes with the surface area of $0.12 \mathrm{~m}^{2}$ is placed inside the storage tank that transmits the heat load of the solar cycle to the consumable water. The specifications of the heat exchanger are given in Table 1.

The experimental setup is equipped with suitable measuring instruments for the performance study of solar water heating system. Eight thermocouples of $\mathrm{K}$ type with an accuracy of $\pm 0.5{ }^{\circ} \mathrm{C}$ were fixed at various locations of the solar collector, storage tank and heat exchanger to measure the temperatures of water passing through the experimental setup and they were connected with an 8 channel digital indicator with a resolution of $0.1^{\circ} \mathrm{C}$. Solar intensity was measured using a solar power meter (Make-TES Electrical electronics, Model-1333, Range-1 to $2000 \mathrm{~W} / \mathrm{m}^{2}$ ). A flow control valve and rotameter were used to control the flow rate and measure the volume flow rate of working fluid respectively. An electrical pump was employed for the circulation of nanofluids.

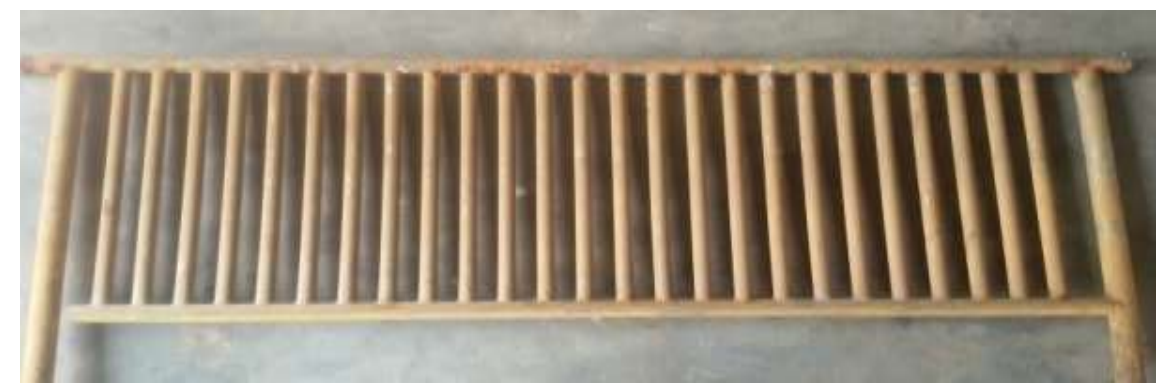

Fig.2. Ladder type Heat Exchanger

Table 1

The specifications of ladder type heat exchanger

\begin{tabular}{|l|l|}
\hline Material & Copper \\
\hline Diameter of the header pipe & $25.4 \mathrm{~mm}$ \\
\hline No. of tubes used (Riser) & $25 \mathrm{Nos}$ \\
\hline Riser tube diameter & $10 \mathrm{~mm}$ \\
\hline Surface area of the heat exchanger & $0.12 \mathrm{~m}^{2}$ \\
\hline
\end{tabular}

Commercial spherical shape copper oxide powders with $99.5 \%$ of purity and an average diameter of $35 \mathrm{~nm}$ was used in this study. In addition, Triton X-100 as natural surfactant for dispersion of copper oxide and distilled water as a base fluid were used in this study. 


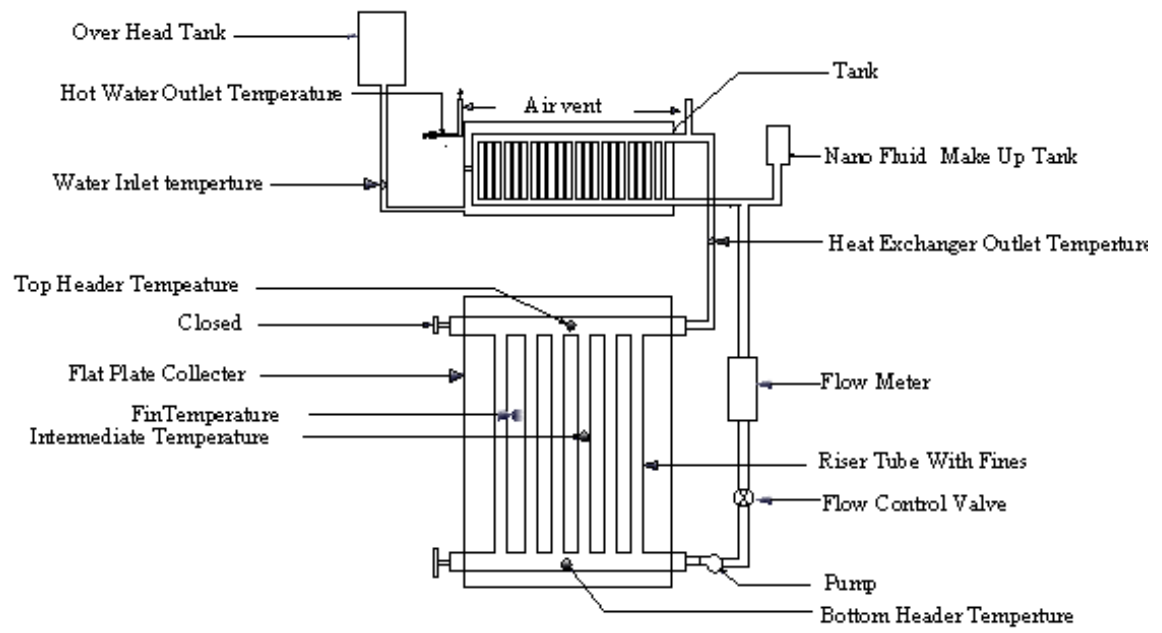

Fig.3. Schematic diagram of the Experimental Setup

\subsection{Calculation}

Based on the energy absorbed by the absorber and the energy lost from the absorber, the useful energy gain $\left(Q_{u}\right)$ was determined by using following Equations (1) and (2).

$$
\mathrm{Q}_{\mathrm{u}}=\dot{m} \mathrm{C}_{\mathrm{p}}\left(\mathrm{T}_{0}-\mathrm{T}_{\mathrm{i}}\right)
$$

where $m$ and $\mathrm{C}_{\mathrm{p}}$ denote mass flow rate and heat capacity of fluid and

$\mathrm{T}_{0}$ and $\mathrm{T}_{\mathrm{i}}$ are the outlet and inlet fluid temperatures of solar collector respectively.

$$
Q_{u}=F_{R}\left[G_{T}(\tau \alpha) \cdot A-U_{l} A\left(T_{i}-T_{a}\right)\right]
$$

Where $F_{\mathrm{R}}$ is heat removal factor, which can be conveniently expressed by the equation (3).

$$
F_{R}=\dot{m} C_{p}\left(T_{i}-T_{a}\right) / G_{T}(\tau \alpha) \cdot A-U_{l} A\left(T_{i}-T_{a}\right)
$$

Where "A" is surface area of the collector, $(\tau \alpha)$ is the absorptance and transmittance product, $\mathrm{G}_{\mathrm{T}}$ is the global solar radiation, $U_{l}$ is the overall loss coefficient of solar collector and $T_{a}$ is the ambient temperature. In equation (3), actual gain of the collector has been related to the usefull energy gain by the collector by considering the collector surface temperature as same as that of the fluid inlet temperature.

A measure of flat plate collector performance is the collector efficiency $(\eta)$ which is defined as the ratio of the useful energy gain $\left(Q_{u}\right)$ to the incident solar energy over a particular time period. Moreover the thermal efficiency $(\eta)$ can be obtained by dividing $Q_{u}$ by the energy input (A.GT) as in equation (4)

$$
\eta=F_{R}\left[G_{T}(\tau \alpha) . A-U_{l} A\left(T_{i}-T_{a}\right)\right] / A G_{T}
$$

\section{RESULTS AND DISCUSSION}

The solar intensity and different components temperatures of solar water heating system for $\mathrm{CuO} /$ water nanofluid at $1.5 \mathrm{lpm}$ during the test days are shown in Fig. 4. Each test was performed in several days and consistent experimental data has been chosen for the calculations.

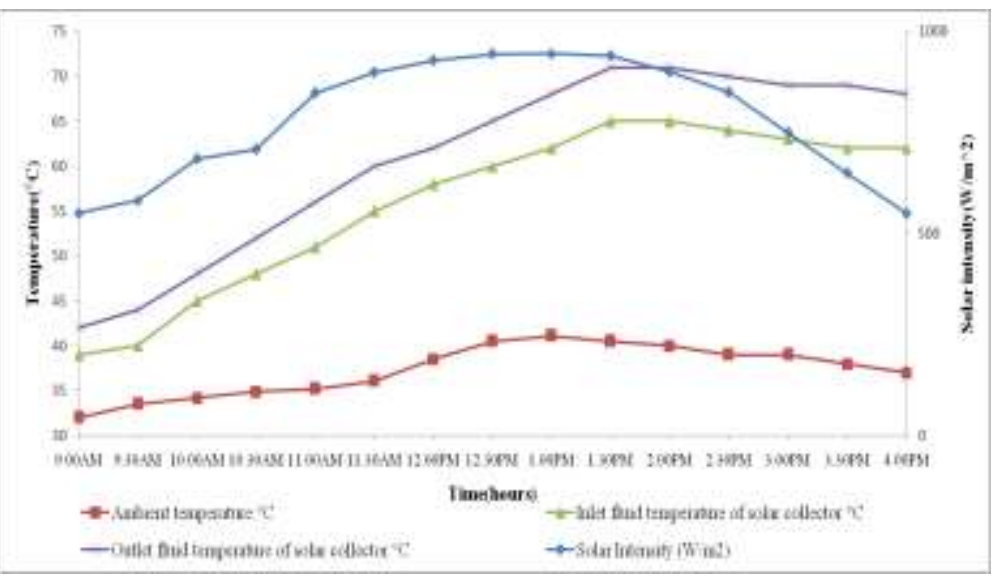

Fig.4. Solar Intensity and different component temperatures of solar water heating system

The heat transfer rate and fin efficiency are dependent of thermal conductivity of material and overall loss coefficient but independent of aspect ratio of absorber plate. Experimental tests have been performed in various flow rates 
with lower volume concentration and Fig.5 shows the experimental data of the thermal absorber fin temperature. The temperature of the copper fins at the inlet side is low during the initial period, but subsequently as the fluid in the riser tube gets heated up and it moves upward and the temperature difference between the fluid and the fin gets reduced. The higher temperature of $\mathrm{CuO} /$ water nanofluid combined with the heat exchanger causes the large temperature difference between the $\mathrm{CuO} /$ water nanofluid and absorber fins. At $1.5 \mathrm{lpm}$ flow rate, fin temperature is low thereby absorbing more heat from the working fluids due to which the heat transferred to the water is higher and fin temperature increases further when flow rate is varied from 2 to $3 \mathrm{lpm}$. Because at lower flow rate, nanofluid gets more time to collect the heat from the absorber plate and hence fin temperature is low. At higher flow rates, nanofluid could not able to collect more heat due to lesser contact time and higher fin temperature. Whereas fin temperature is much higher in the case of distilled water as working fluid as shown in Fig.5. Due to the poor thermal characteristics of distilled water, it is not able to collect more heat from the absorber plate. The heat transfer rate from the absorber plate fin decreases with increase in fluid outlet temperature but increases with increase in overall loss parameter and solar flux.

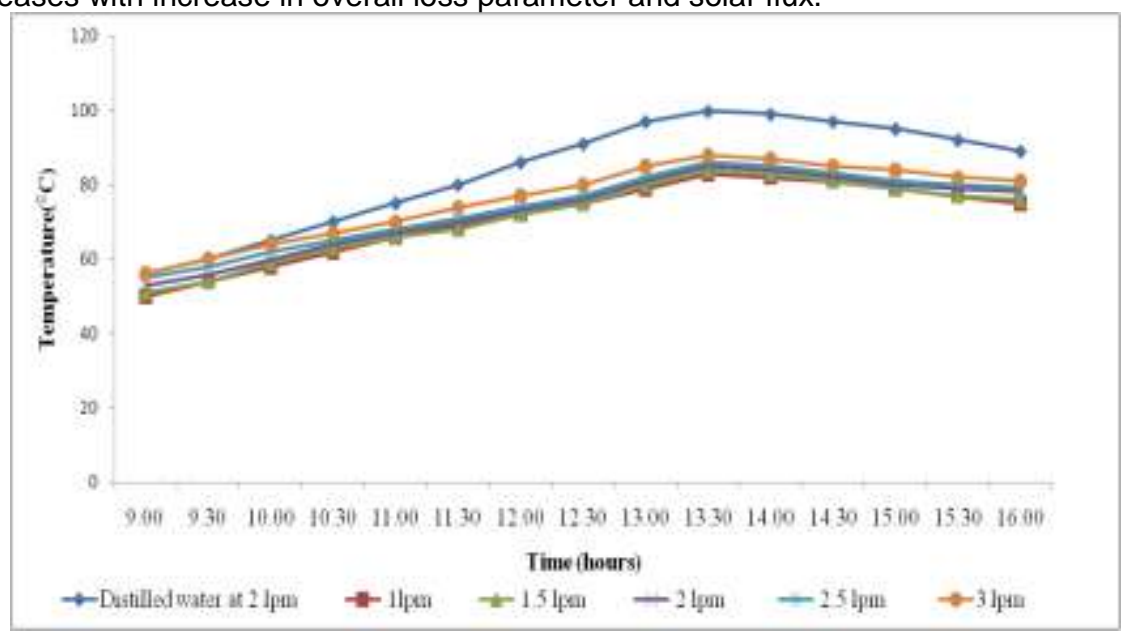

Fig.5. Absorber fin temperature

The thermal storage tank water temperature depends upon the effectiveness of heat exchanger and the inlet and outlet temperature difference of the fluid. The $\mathrm{CuO} /$ water nanofluid in forced circulation produced the highest storage tank temperature of $85.3^{\circ} \mathrm{C}$ at $1.5 \mathrm{lpm}$ as shown in Fig. 6. In contrast, the highest temperature reached using distilled water as the heat transfer fluid in the forced circulation is $70.6{ }^{\circ} \mathrm{C}$, which is less than the $\mathrm{CuO} /$ water nanofluid. The storage tank water temperature rises as the heat is transferred effectively from the CuO/water nanofluid. Because of the very less contact time with the heat exchanger both fluids produced the lesser temperatures in the thermal storage tank at higher flow rates. $\mathrm{CuO} /$ water nanofluid with $0.01 \%$ volume fraction has increased the thermal storage tank useful temperature by $14.7 \%$ when compared to distilled water as the working fluid.

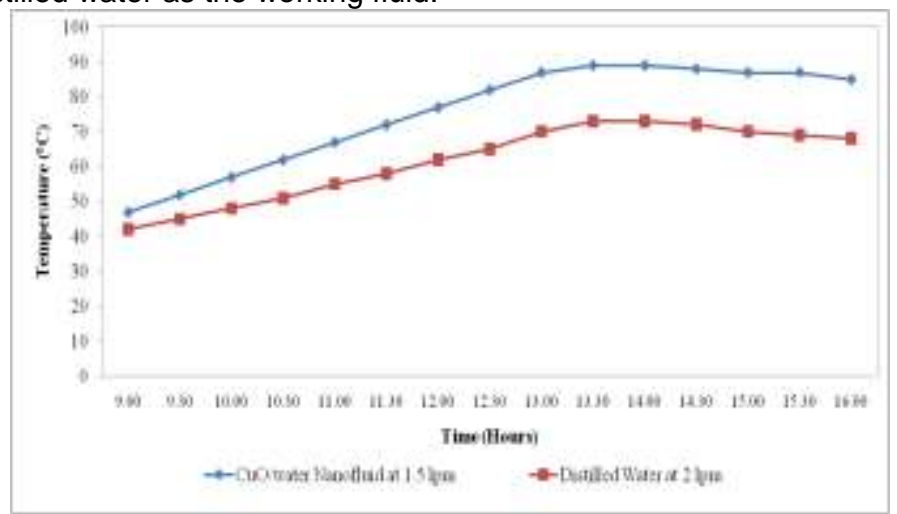

Fig .6. Storage tank temperature

$\mathrm{CuO} /$ water nanofluids were prepared with $0.01 \%$ volume fraction for the investigation of the collector efficiency for various flow rates from $1 \mathrm{lpm}$ to $3 \mathrm{lpm}$. Tests were carried out for all the flow rates with and without surfactant for several days. The efficiency of the flat plate solar collector for various mass flow rates with $\mathrm{CuO} /$ water nanofluid as base fluid is compared with distilled water. The highest efficiency of the solar collector is achieved at $1.5 \mathrm{lpm}$ when $\mathrm{CuO} / \mathrm{water}$ nanofluid is used as the working fluid whereas distilled water has achieved the highest performance for the mass flow rate at $2 \mathrm{lpm}$. The collector efficiency increases with decrease in mass flow rate as more solar energy is absorbed due to low mass flow rate and low velocity. Therefore, it can be concluded that the optimum mass flow rate depends upon the working fluid's thermal characteristics. The highest efficiency of $68.7 \%$ was obtained for the CuO/water nanofluid at 1.5 Ipm flow rate and the efficiency of $49 \%$ was achieved at $2 \mathrm{lpm}$ when distilled water is used as the working fluid. It was also observed that the enhanced performance using $\mathrm{CuO} /$ water nanofluid was significant at low flow rate when compared to high flow rates. When the mass flow rate is increased from $1.5 \mathrm{lpm}$ to $3 \mathrm{lpm}$ the efficiency decreases and shows negative results. 


\section{CONCLUSION}

The performance of a flat plate solar water heating system operated with $\mathrm{CuO} /$ water nanofluid was experimentally investigated and the effect of the nanofluid on the efficiency of the flat plate collector is compared with distilled water. The influence of the mass rate on the flat plate solar water heating system efficiency has been analysed with the selected mass flow rate in the range of 1 to $3 \mathrm{lpm}$. The results show that using $\mathrm{CuO} /$ water nanofluid increases the efficiency of flat plate solar water heating system in comparison with that of water by $19.7 \%$ with the optimum mass flow rate at $1.5 \mathrm{lpm}$. It is also observed that the efficiency of collector decreases about $6.1 \%$ when the flow rate is increased from $1.5 \mathrm{lpm}$ to $3 \mathrm{lpm}$. Based on the thermal characteristics of working fluid, the optimum mass flow rate can be achieved.

\section{Nomenclature}

$\mathrm{A}_{\mathrm{c}} \quad$ Surface area of solar collector $\left(\mathrm{m}^{2}\right)$

$\mathrm{C}_{\mathrm{p}} \quad$ Specific heat at constant pressure $\left(\mathrm{J} / \mathrm{kg}^{\circ} \mathrm{K}\right)$

$\mathrm{G}_{\mathrm{t}} \quad$ Global solar radiation $\left(\mathrm{W} / \mathrm{m}^{2}\right)$

$\dot{m} \quad$ Mass flow rate of fluid flow $(\mathrm{kg} / \mathrm{sec})$

$\mathrm{T}_{\mathrm{a}} \quad$ Ambient Temperature $\left({ }^{\circ} \mathrm{C}\right)$

$\mathrm{T}_{\mathrm{i}} \quad$ Inlet Fluid Temperature of solar collector $\left({ }^{\circ} \mathrm{C}\right)$

$\mathrm{T}_{\mathrm{O}} \quad$ Outlet fluid temperature of solar collector $\left({ }^{\circ} \mathrm{C}\right)$

$\mathrm{T}_{\mathrm{fm}} \quad$ Mean temperature of the working fluid inside the collector $\left({ }^{\circ} \mathrm{C}\right)$

$Q_{u} \quad$ Rate of useful energy gained (W)

$F_{R} \quad$ Heat removal factor

F' Collector efficiency factor

\section{Greek symbols}

\section{$\alpha \quad$ Transmittance of glass cover \\ $\tau \quad$ Absorptance of plate}

\section{REFERENCES}

[1]. Ferrouillat S, Bontemps A, Poncelet O, Soriano O, Gruss J A, Influence of nanoparticle shape factor on convective heat transfer and energetic performance of water-based $\mathrm{SiO}_{2}$ and $\mathrm{ZnO}$ nanofluids,Appl.Therm.Eng.51(2013)839-851.

[2] Kaufui V.Wong and Omar De Leon, Applications of Nanofluids: Current and Future, Article ID 519659, Advances in Mechanical Engineering.Vol. 2010.

[3] Peyghambarzadeh S M, Hashemabadi S H, Naraki M, Vermahmoudi Y, Experimental study of overall heat transfer coefficient in the application of dilute nanofluids in the car radiator, Appl.Therm.Eng.52 (2013) 8-16.

[4] Kole M, Dey T K, Thermal performance of screen mesh wick heat pipes using water based copper nanofluids, Appl.Therm.Eng.50 (2013)763-770.

[5]. Mahian et al, A review of applications of nanofluids in solar energy, Int. J. Heat Mass Transfer. 57 (2013) $582-$ 594.

[6]. Natarajan E, Sathish R, Role of nanofluids in solar water heater, Int. J. Adv. Manuf. Technol, 2009. 10.1007/s00170-008-1876-8.

[7]. Mu L J, Zhu Q Z, Si L L, Radiative properties of nanofluids and performance of a direct solar absorber using nanofluids, in: Proceedings of the 2nd ASME Micro/Nanoscale Heat \& Mass Transfer International Conference,vol.1,2010,pp.549-553.

[8]. Hua Qing Xie, Wei Yu, Jing Li, Yang Li, Investigation on Heat Transfer Performances of Nanofluids in SolarCollector, Materials Science Forum Frontier of Nanoscience and Technology 694(2011) 33-39

[9]. Mahian Omid, Kianifar Ali, Sahin Ahmet Z, Wongwises Somchai, Performance analysis of a minichannel-based solar collector using different nanofluids, Energy Convers Manage.88(2014)129-38.

[10]. Sheikholeslami M, Ganji D D, Rashidi M M, Ferrofluid flow and heat transfer in a semi annulus enclosure in the presence of magnetic source considering thermal radiation, J. Taiwan Inst. Chem. Eng. 47(2015)6-17

[11]. Sheikholeslami M, Ganji M M, Nanofluid flow and heat transfer between parallel plates considering Brownian motion using DTM, Comput. Methods Appl. Mech.Eng.283(2015)651-663.

[12]. Sheikholeslami M, Hatami M, Domairry G, Numerical simulation of two phase unsteady nanofluid flow and heat transfer between parallel plates in presence of time dependent magnetic field,J.TaiwanInst.Chem.Eng.46(2015)43-50.

[13]. Sheikholeslami M, KKL correlation for simulation of nanofluid flow and heat transfer in a permeable channel, Phys.Lett.A378 (2014)3331-3339.

[14]. Sheikholeslami M, Effect of spatially variable magnetic field on ferrofluid flow and heat transfer considering constant heat flux boundary condition, Eur. Phys. J. Plus 129 (2014) 248.

[15] Saidur R, Meng T C, Said Z, Hasanuzzaman M, Kamyar A, Evaluation of the effect of nanofluid-based absorbers on direct solar collector, Int. J. Heat Mass Transfer. 55(2012)5899-907.

[16] Buongiorno J, Convective transport in nanofluids, J Heat Transfer 2005;128 (3):240-50. 